Article

\title{
Copper-Electroplating-Modified Liquid Metal Microfluidic Electrodes
}

\author{
Jiahao Gong ${ }^{1,2}$, Bingxin Liu ${ }^{1,3}$, Pan Zhang ${ }^{1,3}$, Huimin Zhang ${ }^{1,3}$ and Lin Gui 1,3,*(D) \\ 1 Liquid Metal and Cryogenic Biomedical Research Center, Technical Institute of Physics and Chemistry, \\ Chinese Academy of Sciences, 29 Zhongguancun East Road, Haidian District, Beijing 100190, China; \\ gongjiahao18@mails.ucas.ac.cn (J.G.); liubingxin17@mails.ucas.ac.cn (B.L.); \\ zhangpan18@mails.ucas.ac.cn (P.Z.); zhanghuimin19@mails.ucas.ac.cn (H.Z.) \\ 2 CAS Key Laboratory of Bio-Inspired Materials and Interfacial Science, Technical Institute of Physics \\ and Chemistry, Chinese Academy of Sciences, 29 Zhongguancun East Road, Haidian District, \\ Beijing 100190, China \\ 3 University of Chinese Academy of Sciences, 19 Yuquan Road, Shijingshan District, Beijing 100039, China \\ * Correspondence: lingui@mail.ipc.ac.cn; Tel.: +86-10-8254-3483
}

Citation: Gong, J.; Liu, B.;

Zhang, P.; Zhang, H.; Gui, L.

Copper-Electroplating-Modified

Liquid Metal Microfluidic Electrodes. Sensors 2022, 22, 1820. https:/ / doi.org/10.3390/s22051820

Received: 24 January 2022

Accepted: 21 February 2022

Published: 25 February 2022

Publisher's Note: MDPI stays neutral with regard to jurisdictional claims in published maps and institutional affiliations.

Copyright: (C) 2022 by the authors. Licensee MDPI, Basel, Switzerland. This article is an open access article distributed under the terms and conditions of the Creative Commons Attribution (CC BY) license (https:// creativecommons.org/licenses/by/ $4.0 /)$.

\begin{abstract}
Here, we report a novel technology for the fabrication of copper-electroplating-modified liquid metal microelectrodes. This technology overcomes the complexity of the traditional fabrication of sidewall solid metal electrodes and successfully fabricates a pair of tiny stable solid-contact microelectrodes on both sidewalls of a microchannel. Meanwhile, this technology also addresses the instability of liquid metal electrodes when directly contacted with sample solutions. The fabrication of this microelectrode depends on controllable microelectroplating of copper onto the gallium electrode by designing a microelectrolyte cell in a microfluidic chip. Using this technology, we successfully fabricate various microelectrodes with different microspacings (from $10 \mu \mathrm{m}$ to $40 \mu \mathrm{m}$ ), which were effectively used for capacitive sensing, including droplet detection and oil particle counting.
\end{abstract}

Keywords: electroplating; liquid metal microelectrodes; capacitive sensing

\section{Introduction}

Metal microelectrodes are essential parts of microfluidic systems. Microfluidic chips integrated with microelectrodes can be used for sample detection [1,2], drug delivery [3-5], cell screening [6-8], droplet manipulation [9,10], and microfluidic fuel cells [11,12]. The fabrication of metal microelectrodes depends on a variety of microfabrication technologies. The selection of appropriate microfabrication processes can meet the shape, size, and sensitivity requirements in microelectrode manufacturing and related application fields. Among them, sidewall microelectrodes [13-15] are widely used in microfluidic systems. They can produce uniform lateral electric fields along the vertical direction in the channel, which is commonly used for electrochemical sensing [16-18], electrical impedance sensing [19,20], capacitive sensing [21-23], among other applications [24].

Sidewall microelectrodes are usually fabricated by patterning the metal film on a flat substrate prior to sealing. There are several methods to fabricate metal thin-film electrodes on sidewalls. One of the approaches is to use shadow masks to pattern metal films at a certain angle. Kang et al. [15] utilized shadow effects occurring during angled evaporation through a shadow mask to deposit the metal films on sidewalls. Choi et al. [25] patterned 3D sidewall electrodes by ion implantation at a $40^{\circ}$ angle with a metal shadow mask. This approach is complex and requires precise alignment technology, resulting in poor sealing. Chemical deposition can also be used to fabricate sidewall metal thin-film electrodes. Kadilak et al. [14] presented an approach to selectively deposit chemically bonded gold electrodes onto PDMS microchannel sidewalls. However, this approach requires multistep chemical reactions in the microchannel, with high cost. Other approaches to fabricate 
sidewall electrodes include electrodeposition [26] and ion milling [27]. They both require specialized equipment and complicated processes.

Injection of low melting point metals or alloys in microchannels is a cheap and effective way to fabricate microelectrodes [28-30] because it avoids multistep fabrication and complex alignment processes. The microelectrode shape is only determined by the shape of the microchannel through lithography. Liquid metals such as gallium and gallium-based alloys are commonly used injectable metals. Dickey et al. [30] utilized eutectic gallium indium (EGaIn) to fabricate a sidewall microelectrode in direct contact with a microfluidic channel. This sidewall microelectrode is easy to fabricate and flexible, it does not have an alignment process, and it enhances the intensity of the applied electric field, which is more effective for sorting, mixing, and amplifying electric signals for sensing.

However, the EGaIn liquid metal contact electrode has poor stability because it is highly prone to deformation when contacting fluids with pressure, resulting in electrode damage. In addition, liquid metal surfaces subjected to acid or alkali cause chemical corrosion, creating defects in the electrode. Instead of using EGaln, using pure gallium or bismuth-based alloys [31-33] with higher melting points can effectively resolve electrode deformation due to pressure because they are solid electrodes at room temperature. However, they are also intolerant of acid and alkali. Another limitation is that none of the above-mentioned electrodes can be fabricated to arbitrarily reduce the spacing between them. Thus, the detection sensitivity of the electrodes cannot be further improved. Therefore, we propose that if an inert metal with a high melting point is coated on the liquid metal's surface, not only can the electrodes' stability be increased, but their shapes and space can be further modified.

Microelectroplating [34-37] is a standard method to prepare or modify microelectrodes. It is a simple processing technology that can fabricate metal microelectrodes with more complex shapes and higher accuracy through a controllable electrochemical process. Bao et al. [35] proposed a method of electroplating $\mathrm{Ag} / \mathrm{AgCl}$ to modify the microelectrode array for application in neural prosthesis. The prepared $\mathrm{Ag} / \mathrm{AgCl}$ microelectrode has a higher charge storage capacity than the unmodified microelectrode, and the impedance decreases significantly. Polk et al. [36] utilized microelectroplating of silver on sharp edges to occlude large $\left(103 \mathrm{~mm}^{2}\right)$ vias in silicon substrates and leave open areas less than $1 \mu \mathrm{m}^{2}$. The formation of solid-state micropores by this method is advantageous in microfluidics systems. However, the modification of a liquid metal microelectrode by microelectroplating technology on a microfluidic chip has not been reported before.

According to the fabrication of liquid metal contact electrodes and microelectroplating technology, this paper proposes a microfabrication technology for copper plating on sidewall gallium microelectrodes by designing a microelectrolyte cell on a microfluidic chip. This technology combines the advantages of easy fabrication of liquid metal electrodes and copper's stable properties. The single-layer pair electrode structure evades complex alignment processes. In addition, since the plating process is performed after chip fabrication and packaging, the desired electrode-to-electrode spacing within 10-40 $\mu \mathrm{m}$ can be achieved by controlling the copper plating thickness, resulting in a suitable range of electrical signals to satisfy different detection requirements. Finally, this electroplated microelectrode pair is used for droplet capacitance detection and metal particle counting in oil. The results show that it can detect the $\Delta \mathrm{C}$ ranging from $11 \mathrm{fF}$ to $17 \mathrm{fF}$ when the droplet length is within $68-248 \mu \mathrm{m}$ and the $\Delta \mathrm{C}$ ranging from $0.9 \mathrm{fF}$ to $1.5 \mathrm{fF}$ when the oil particle size is approximately within $8-15 \mu \mathrm{m}$. It suggests that microspacing sidewall microelectrodes based on liquid metal electroplating has great potential in particle detection.

\section{Experimental Details}

\subsection{Design of the Chip}

The design of a sidewall microelectroplated chip is based on the principle of an electrolytic cell. The chip consists of two polydimethylsiloxane elastomer (PDMS) slabs $(2.5 \mathrm{~cm}$ long, $1.5 \mathrm{~cm}$ wide and $2.5 \mathrm{~mm}$ high), as shown in Figure 1a. Figure $1 \mathrm{~b}$ shows the upper-layer 
structure of the chip. It consists of a transverse and two V-shaped electrode microchannels, both $50 \mu \mathrm{m}$ high. The transverse microchannel includes an electrolyte inlet, an outlet, and a circular area (1.3 $\mathrm{mm}$ in diameter). The center of its circular area has a round hole $(1.2 \mathrm{~mm}$ in diameter) used as a copper wire jack. Two V-shaped electrode microchannels are symmetrically distributed on both sides of the transverse flow channel. The microstructure in the V-shaped electrode microchannel is shown in the enlarged part of Figure 1b. A trapezoidal microgap (upper base: $28 \mu \mathrm{m}$ wide) is set at the bottom of the electrode channel to avoid overflow of the liquid metal electrode. A rectangular microchannel (50 $\mu \mathrm{m}$ long and $28 \mu \mathrm{m}$ wide) lies below the trapezoidal gap as an electroplating zone. After electroplating, it is connected with the transverse channel to form the contact electrode. The lower PDMS slab works as an encapsulation layer without any structure.
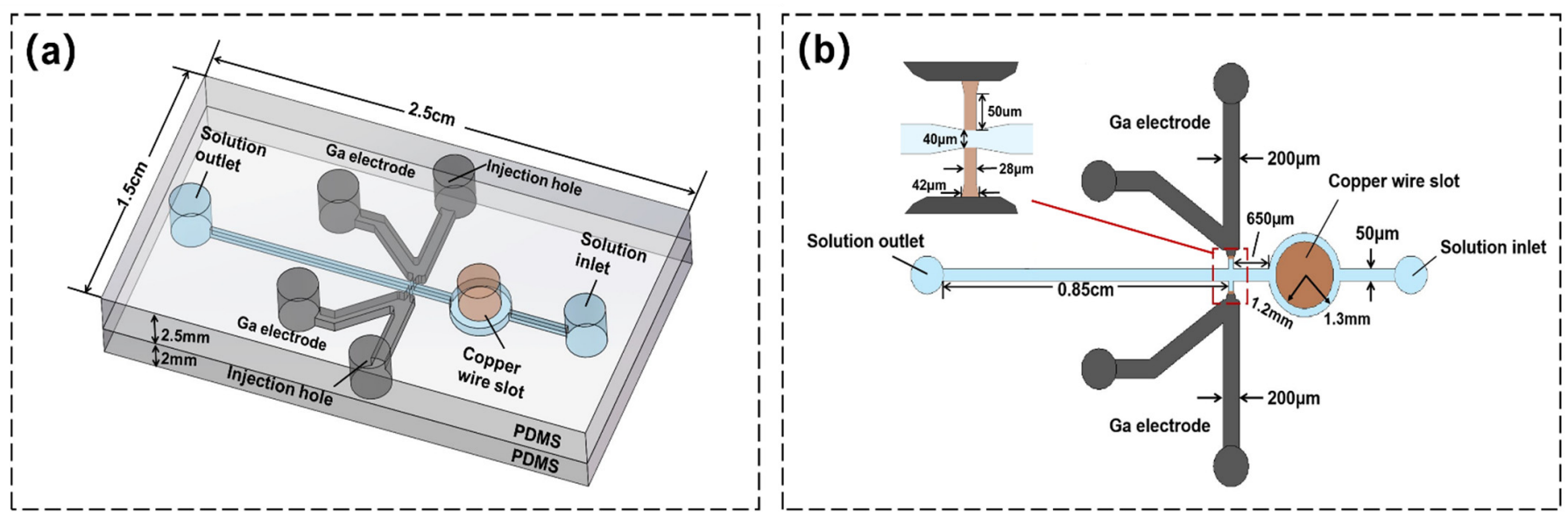

Figure 1. Chip structure diagram: (a) 3D structure diagram of the chip. (b) Plane diagrammatic sketch of the chip. The transverse electroplating solution microchannel is $50 \mu \mathrm{m}$ wide. The electrode microchannel is $200 \mu \mathrm{m}$ wide. The diameter of the circular microchannel is $1.3 \mathrm{~mm}$, and the diameter of copper wire is $1.2 \mathrm{~mm}$. The vertical distance from the circular channel to the electrode is $650 \mu \mathrm{m}$. For the microstructure part, the upper bottom of the trapezoidal gap is $42 \mu \mathrm{m}$. The lower bottom is $28 \mu \mathrm{m}$. The rectangular area is $28 \mu \mathrm{m}$ wide and $50 \mu \mathrm{m}$ long. The microchannel width between the electrode areas is $40 \mu \mathrm{m}$.

\subsection{Fabrication of the Chip}

The sidewall microelectroplated chip was fabricated using standard soft lithography. First, a photoresist SU-8 2050 (MicroChem Corp., Westborough, MA, USA) was used to mold a microchannel with the height of $50 \mu \mathrm{m}$ on a silicon wafer (Ultrapak $100 \mathrm{~mm}$, Fengcheng, Kaihua, China ). Second, the PDMS (a mixture of a base and a curing agent at a ratio of 10:1 by weight, Dow Corning, Midland, MI, USA) was cast on the silicon wafer and then baked at $75{ }^{\circ} \mathrm{C}$ for $1.5 \mathrm{~h}$. After that, the microchannel pattern could be transferred to the PDMS surface. Third, the PDMS was cut into cuboid slabs $(2.5 \mathrm{~cm} \times 1.5 \mathrm{~cm} \times 2.5 \mathrm{~mm})$ containing the entire microchannel and peeled off from the silicon wafer. Fourth, another PDMS slab without any structures $(2.5 \mathrm{~cm} \times 1.5 \mathrm{~cm} \times 2 \mathrm{~mm})$ was used for plasma bonding with the upper structural layer to seal the microchannel (plasma cleaner, YZD08-2C, Tangshan Yanzhao Technology, Tangshan, China). Gallium (melting point: $29.8^{\circ} \mathrm{C}$; Shanxi Zhaofeng Gallium Co., Ltd., Quanyang, China) was firstly heated to liquid. The quantitative volume of liquid metal gallium was extracted by syringe and injected into a V-type electrode microchannel. Then, four wires $(10 \mathrm{~cm}$ long and $0.2 \mathrm{~mm}$ diameter $)$ were inserted into four holes of microelectrode channels, respectively. Another copper wire (1.2 mm diameter) was inserted into the copper wire slot. A 705 glue was used to seal all the wires. After the 705 glue curing, the sidewall microelectroplated chip was complete (the process is also shown in Figure S1). Finally, the chip was stored in a refrigerator at $-80^{\circ} \mathrm{C}$ to solidify the liquid metal gallium. 


\subsection{Method of Microelectroplating}

The microchip was taken out from the refrigerator and observed under a microscope (Axio Observer Z1, Carl Zeiss, Oberkochen, German). A multimeter was used to check the conductivity of the electrode. The microelectroplating process is shown in Figure 2a. A four-channel microfluidic control system (MFCSTM-EZ, FLUIGENT, Paris, France) was used to pump the $\mathrm{CuSO}_{4}$ solution into the transverse microchannel. The pumping pressure was maintained at 300 mbar. After draining all the microchannel bubbles, $\mathrm{CuSO}_{4}$ solution could fill the entire electroplating region and fully contact the gallium surface. Next, the positive pole of a DC power supply (IT6720, $60 \mathrm{~V} / 5 \mathrm{~A} / 100 \mathrm{~W}$, ITECH, Taiwan, China) was connected with the copper wire, and the negative pole was connected with the wire on one side of the gallium electrode. Based on the principle of an electrolytic cell, copper worked as a sacrificial metal that lost electrons and transformed into $\mathrm{Cu}^{2+}$ to enter the electrolyte. Secondly, the gallium cathode was continuously supplied with electrons through impressed current cathodic protection, inhibiting a self-corrosion reaction. Subsequently, $\mathrm{Cu}^{2+}$ migrated to the gallium surface to capture electrons to form $\mathrm{Cu}$ and deposited on the gallium surface, forming the copper coating. The copper layer continuously grew until the entire electroplating area was filled before stopping the process. The other side of the gallium electrode was electroplated in the same way. After electroplating on both sides of the electrode, DI water was continuously pumped into the electrolyte microchannel for $20 \mathrm{~min}$ to wash off the residual $\mathrm{CuSO}_{4}$ solution. Finally, the sidewall microelectroplating electrode pair was prepared with spacing of only $40 \mu \mathrm{m}$. (Figure $2 \mathrm{~b}$ shows the actual diagram of the process).

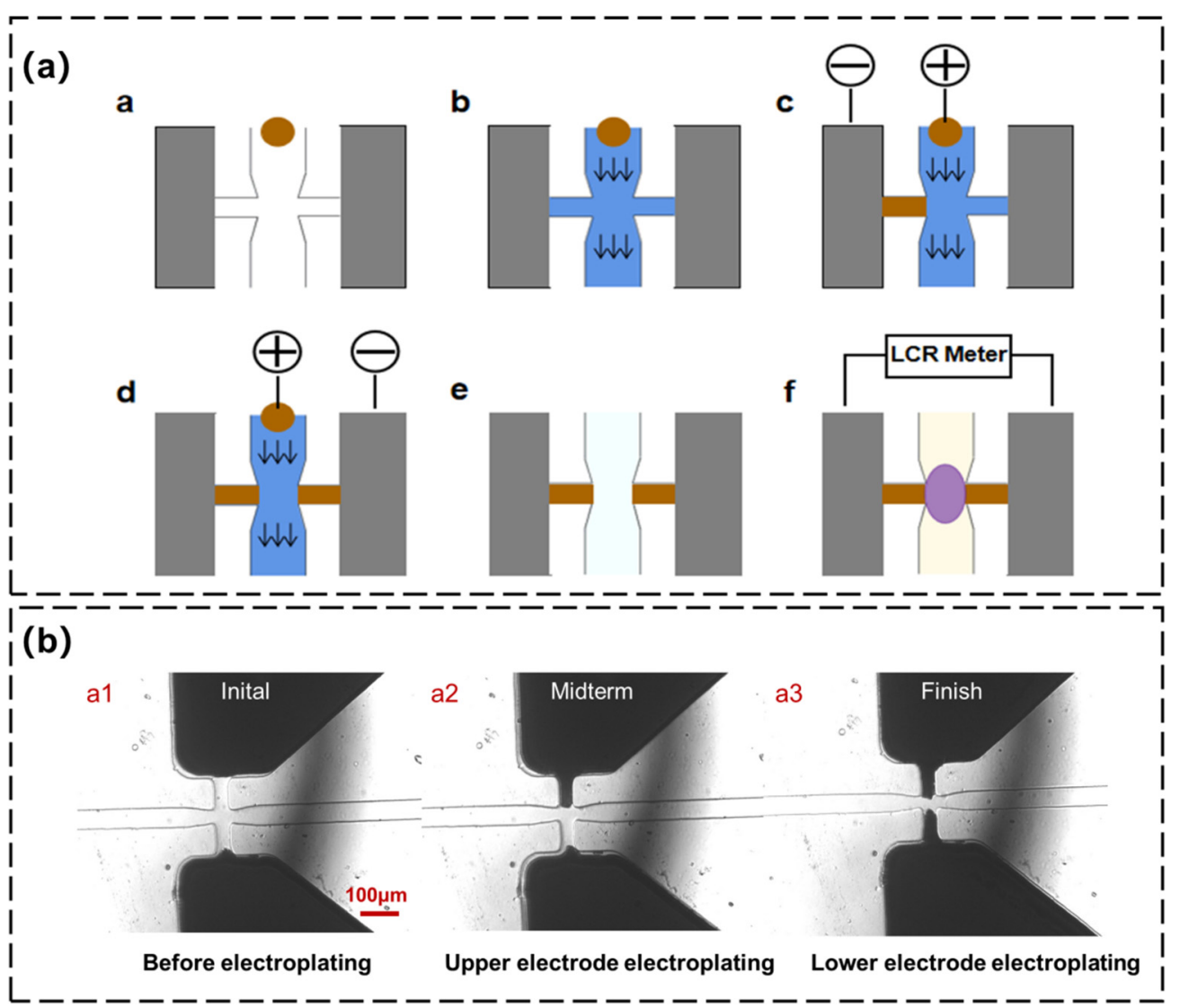

Figure 2. Microelectroplating process: (a) Microelectroplating steps: a. the initial state of the microelectrode; b. pumping $\mathrm{CuSO}_{4}$ solution; . Ga electrode plating on one side; $\mathbf{d}$. Ga electrode plating on the other side; e. DI water cleaning; f. applications after electroplating. (b) Actual diagram of electroplating process. Subfigures a1, a2 and a3 were plating conditions at different stages. 


\section{Results and Discussion}

\subsection{Effects of Electroless Plating}

In the nonelectroplating process, when the gallium surface contacts the $\mathrm{CuSO}_{4}$ solution directly at room temperature, the oxidation-reduction reaction between $\mathrm{Ga}$ and $\mathrm{Cu}^{2+}$ can also occur, forming electroless plating. In addition, the electroless plating degree becomes more significant by increasing the concentration of $\mathrm{CuSO}_{4}$ solution, which seriously affects electroplating in this work because each electrode was electroplated separately. Consequently, when one of the electrodes was electroplated, the opposite electrode also contacted $\mathrm{CuSO}_{4}$ solution, forming the electroless plating, which resulted in the uncontrolled spontaneous growth of the copper layer. The effect of electroless plating on electroplating is shown in Figure 3a. However, the experimental results show that the low concentration of $\mathrm{CuSO}_{4}$ solution resulted in very weak electroless plating. Since the electroplating efficiency was much higher than that of electroless plating, the hazards of uncontrolled electroless plating could be minimized. Figure 3b,c show the microelectrodes' morphology and electroless plating area curve over $20 \mathrm{~min}$ at different $\mathrm{CuSO}_{4}$ concentrations, respectively. The pump-in pressure of the $\mathrm{CuSO}_{4}$ solution was set at 300 mbar. When the concentration of $\mathrm{CuSO}_{4}$ was only $10 \%$, the copper layer growth area was only about $130 \mu \mathrm{m}^{2}$ in $20 \mathrm{~min}$. However, with the $\mathrm{CuSO}_{4}$ concentration increasing to $20 \%$, the copper layer area could reach about $1052 \mu \mathrm{m}^{2}$ in $20 \mathrm{~min}$. Therefore, choosing $10 \% \mathrm{CuSO}_{4}$ as an electroplating solution was advantageous to eliminate the influence of electroless plating.

(a)

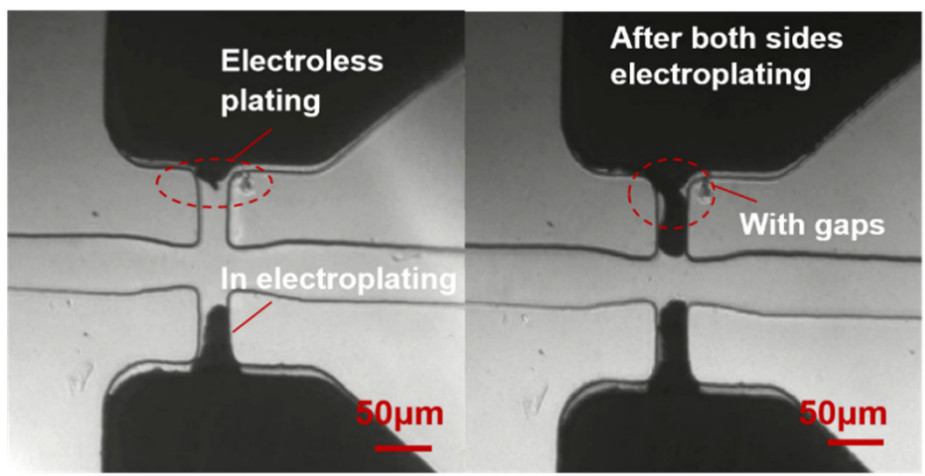

(b)

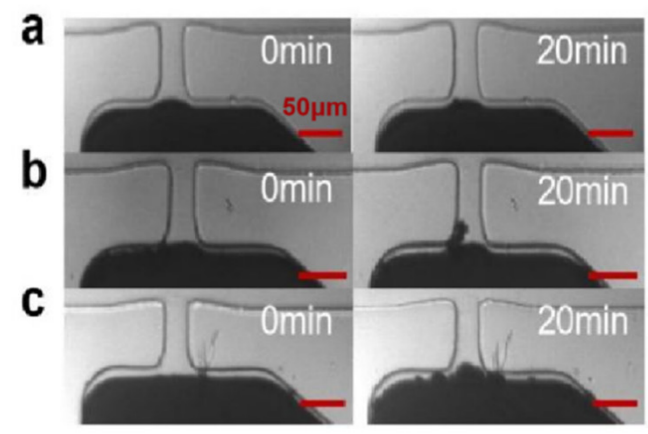

(c)

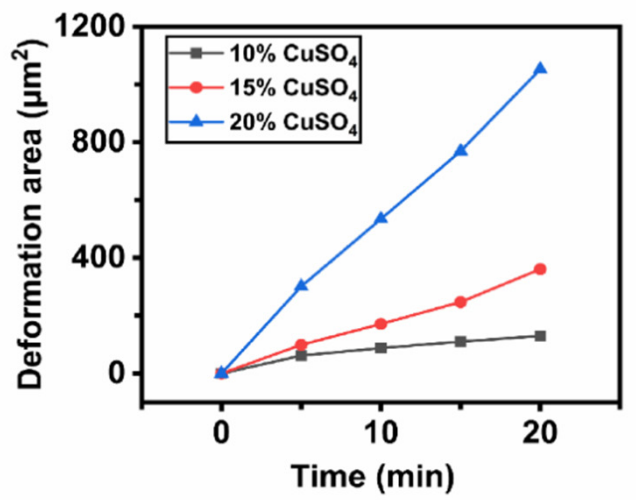

Figure 3. Effect of electroless plating: (a) Effect of electroless plating on the microelectroplating process by $\mathrm{CuSO}_{4}$ with high concentration. (b) Electroless plating conditions of microelectrodes over 20 min at different $\mathrm{CuSO}_{4}$ concentrations: a. $10 \% \mathrm{CuSO}_{4} ;$ b. $15 \% \mathrm{CuSO}_{4} ;$ c. $20 \% \mathrm{CuSO}_{4}$. (c) Electroless plating areas at different $\mathrm{CuSO}_{4}$ concentrations. 


\subsection{Voltage Effects on Microelectroplating}

When the $\mathrm{CuSO}_{4}$ concentration is constant, the relationship between copper plating thickness, current density, and plating time is followed by the formula:

$$
\mathrm{L}=\mathrm{K} \cdot \mathrm{D}_{\mathrm{K}} \cdot \mathrm{t} \cdot \eta_{\mathrm{K}}
$$

where $\mathrm{L}$ is plating thickness $(\mu \mathrm{m}), \mathrm{K}$ is thickness coefficient, $\mathrm{D}_{\mathrm{K}}$ is cathode current density, $t$ is plating time, and $\eta_{K}$ is cathode current density efficiency. The thickness coefficient $K$ is determined by plating metal chemical equivalent $\alpha$ and plating metal density $\gamma$ :

$$
\mathrm{K}=\alpha / \gamma
$$

This work calculates $\mathrm{K}$ as $0.133 \mathrm{~cm}^{3} / \mathrm{ah}$ according to a divalent copper ion chemical equivalent of $1.186 \mathrm{~g} / \mathrm{ah}$ and a copper density of $8.9 \mathrm{~g} / \mathrm{cm}^{3}$.

Formula (1) suggests that the plating thickness has a linear relationship with the plating time and that the electrodeposition rate $\mathrm{V}\left(=\mathrm{K} \cdot \mathrm{D}_{\mathrm{K}} \cdot \eta_{\mathrm{K}}\right)$ increases with the increase of current density. However, the required current density is minimal since this work was microplating at the microchannel with an extremely tiny plating area $(50 \mu \mathrm{m} \times 28 \mu \mathrm{m})$. Therefore, the current delivered by the DC power supply cannot be reflected. However, the voltage provided by the DC power supply is proportional to the output current due to the specific internal resistance. Therefore, the plating thickness is also proportional to the voltage.

The copper layer growth of microelectrodes at different voltages was recorded by photography (shown in Figure S3). Figure 4a shows the thickness variation of the copper layer with time on one of the electrodes at $0.6 \mathrm{~V}$, and the time required for the copper layer to fill the electroplating zone was $540 \mathrm{~s}$. Figure $4 \mathrm{~b}$ shows the thickness variation of the copper layer with time at different applied voltages. The copper layer thickness increased approximately linearly under the different plating voltages of $0.6,0.8$, and $1.0 \mathrm{~V}$. The times required for the copper layer thicknesses to reach the maximum value were $540 \mathrm{~s}, 390 \mathrm{~s}$, and $240 \mathrm{~s}$, respectively. Their electroplating rates were calculated to be $0.13 \mu \mathrm{m} / \mathrm{s}, 0.18 \mu \mathrm{m} / \mathrm{s}$, and $0.31 \mu \mathrm{m} / \mathrm{s}$, respectively.

(a)

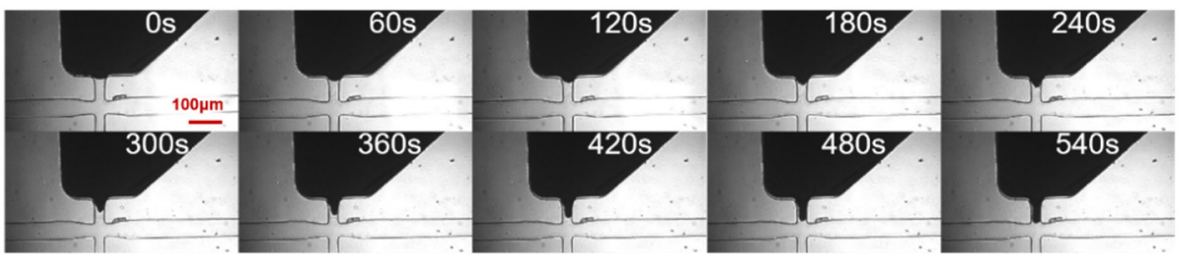

(b)

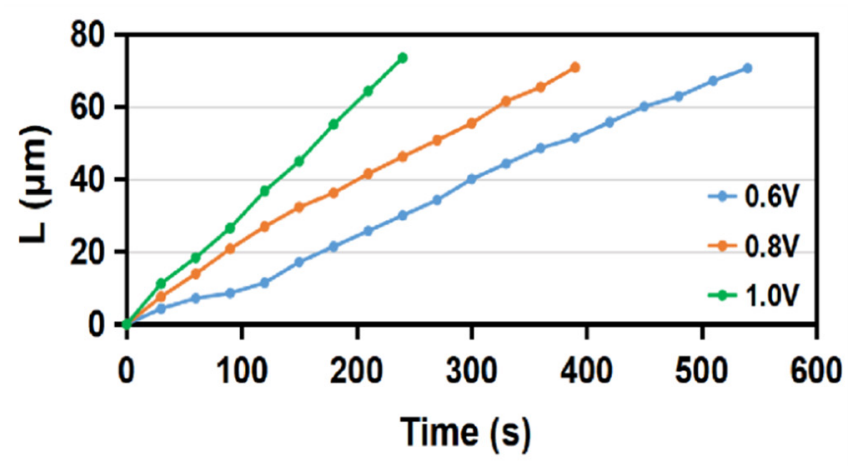

(c)

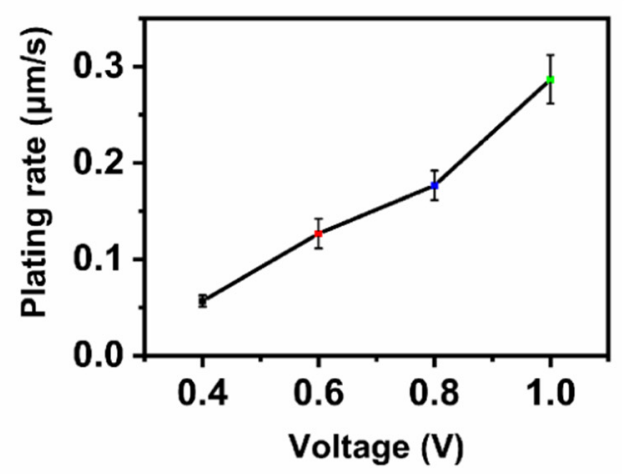

Figure 4. Effect of voltage on microplating: (a) Photograph of copper layer growth with time at $0.6 \mathrm{~V}$. (b) The curve of copper layer thickness versus time at different voltages. (c) Average electroplating rate at different applied voltages. 
Figure $4 \mathrm{c}$ shows the average electroplating rate curve of the copper layer at different electroplating voltages $(0.4,0.6,0.8$, and $1.0 \mathrm{~V})$. The copper plating rate increased with the increase of voltage. The average electroplating rate at $0.4,0.6,0.8$, and $1.0 \mathrm{~V}$ was $0.06 \mu \mathrm{m} / \mathrm{s}$, $0.13 \mu \mathrm{m} / \mathrm{s}, 0.18 \mu \mathrm{m} / \mathrm{s}$, and $0.29 \mu \mathrm{m} / \mathrm{s}$, respectively. However, suppose the voltage (>1 V) continued to increase. In that case, the plating rate might become less controllable. The copper layer might be less dense with the risk of copper dendrite generation. Consequently, in the actual microplating process, the ideal plating voltage range was from $0.6 \mathrm{~V}$ to $1 \mathrm{~V}$.

\subsection{Microelectrode Stability}

To verify whether the Cu-plated Ga microelectrode had better stability than other common liquid metal microelectrodes, we compared the $\mathrm{Cu}$-plated $\mathrm{Ga}$ microelectrode with the EGaIn and Ga solid microelectrodes. The deformation degrees of these three kinds of electrodes were tested at different pressures or temperatures.

In the pressure resistance test, DI water $\left(25^{\circ} \mathrm{C}\right)$ was pumped into the transverse microchannel at different pressures (200 mbar, 250 mbar, 300 mbar, and 350 mbar) by using the four-channel microfluidic system, and a microscope was used to observe and record their electrode conditions over $30 \mathrm{~s}$ at different pressures. Then, the deformation areas were estimated based on pixel points of the images. The EGaIn electrode began to deform at $200 \mathrm{mbar}$ at $25^{\circ} \mathrm{C}$, and the deformation area was about $7505 \mu \mathrm{m}^{2}$, as shown in Figure 5a. No deformations occurred at this pressure interval for the Ga solid electrode or the $\mathrm{Cu}$-plated Ga electrode, demonstrating that these solid electrodes have higher pressure resistance at room temperature.

(a)

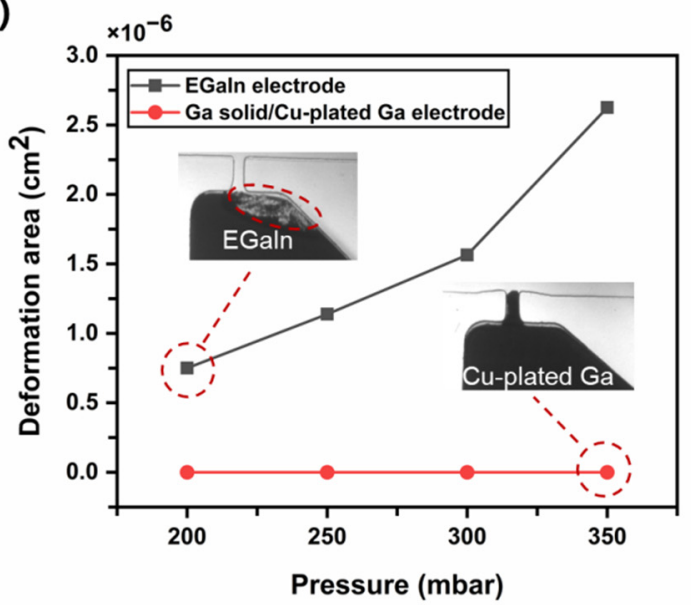

(b)

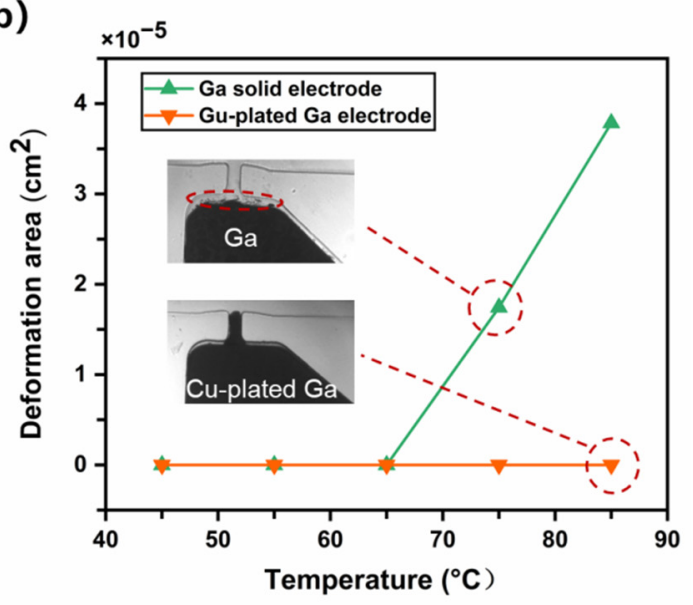

Figure 5. Pressure and temperature resistance tests of different microelectrodes: (a) Pressure resistance comparison between EGaIn and Ga solid/Cu-plated Ga electrodes at $25^{\circ} \mathrm{C}$. (b) Temperature resistance comparison between Ga solid electrode and Cu-plated Ga electrode at 300 mbar.

Furthermore, the Ga solid electrode and the Cu-plated Ga electrode were used for the temperature resistance test. DI water with different inlet temperatures $\left(45^{\circ} \mathrm{C}, 55^{\circ} \mathrm{C}\right.$, $65^{\circ} \mathrm{C}, 75^{\circ} \mathrm{C}$, and $85^{\circ} \mathrm{C}$ ) was pumped into the transverse microchannel at $300 \mathrm{mbar}$, and the microscope was used to observe and record the electrode conditions over $30 \mathrm{~s}$. Figure $5 \mathrm{~b}$ shows that the Ga solid electrode began to deform at $75^{\circ} \mathrm{C}$ and the deformation area was about $1744 \mu \mathrm{m}^{2}$ because the Ga surface began to melt, resulting in poor pressure resistance. In contrast, the $\mathrm{Cu}$-plated $\mathrm{Ga}$ electrode exhibited better temperature resistance, with no electrode deformation from $45^{\circ} \mathrm{C}$ to $85^{\circ} \mathrm{C}$, attributed to the $\mathrm{Cu}$ layer protection on the low melting point $\mathrm{Ga}$. In this case, the DI water with high temperature and pressure could not directly contact the Ga surface to induce deformation. Therefore, the experiment shows that the $\mathrm{Cu}$-plated Ga microelectrode has better performance in both pressure and temperature resistance. 


\subsection{Fabrication of Microelectrodes with Different Spacings}

Electrodes of different microdistances can also be fabricated using this microelectroplating method to meet different detection accuracies. We successfully fabricated microelectrodes with the distances of $40 \mu \mathrm{m}, 30 \mu \mathrm{m}, 20 \mu \mathrm{m}$, and $10 \mu \mathrm{m}$, as shown in Figure 6 . In the fabrication process, the microscope was used to observe the growth of the copper layer. For the distance of $40 \mu \mathrm{m}$, we needed to ensure that the coatings of the upper and lower electrodes filled the whole plating area. However, for the distances of $30 \mu \mathrm{m}, 20 \mu \mathrm{m}$, and $10 \mu \mathrm{m}$, the coatings needed to grow into the microchannel. Taking the fabrication of electrodes with a distance of $30 \mu \mathrm{m}$ as an example, the upper electrode was first electroplated with the voltage of $0.6 \mathrm{~V}$. After filling the plating area, an extra $5 \mu \mathrm{m}$ was expected to grow in the vertical direction. Therefore, the required growth location was calibrated in advance, and when the copper layer arrived here, the plating of the upper electrode was stopped. Next, the same electroplating method was used for the lower electrode. Finally, we acquired the electrodes with a gap of $30 \mu \mathrm{m}$ between each.

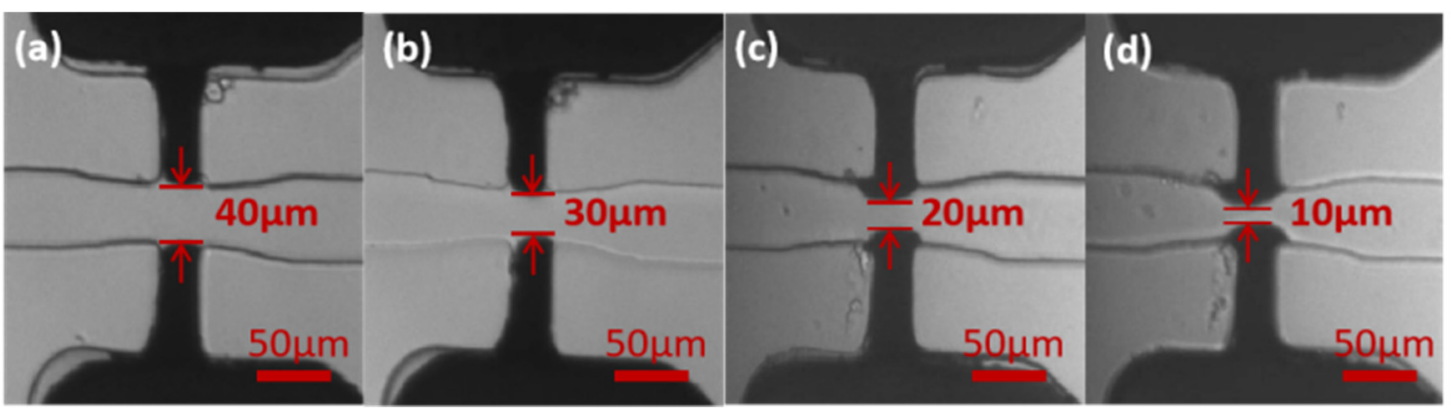

Figure 6. The fabrication of microelectrodes with different microdistances: (a) $40 \mu \mathrm{m}$ spacing; (b) $30 \mu \mathrm{m}$ spacing; (c) $20 \mu \mathrm{m}$ spacing; (d) $10 \mu \mathrm{m}$ spacing.

\section{Applications}

\subsection{Droplet Detection}

Based on the microdistance structure of liquid metal microelectroplated sidewall electrodes, small capacitance changes can be detected, such as capacitance changes of droplets with different lengths. Therefore, we fabricated a droplet capacitive microsensor that contained the microdistance electrodes. This microsensor was constructed by adding a T-shaped microchannel to the previously introduced microelectroplating chip shown in Figure 7a. The T-shaped microchannel generated water-in-oil droplets (dimethyl silicone oil is the continuous phase, and DI water is the discrete phase). The corresponding capacitance signal was generated when droplets passed through the sensing area containing electroplated electrodes. Figure $7 \mathrm{~b}$ shows the construction of an experimental instrument. First, a four-channel microfluidic control system was used to pump the electrolyte, and a DC power supply was used to apply voltages for electroplating. The microfluidic control system was used again to adjust the oil pressure and DI water to generate uniform water-in-oil droplets of different lengths after the electroplating. The microelectrodes were connected with an LCR meter (TH2817A, Precision LCR Meter, Shenzhen, China) to detect capacitance signals. The data were recorded in the computer's LabVIEW program. The microscope was used to observe the optical results during the whole process.

The capacitance change caused by a droplet is due to permittivity variation between microelectrodes. The relative permittivity values of DI water and dimethyl silicone oil are 81 and 2.5, respectively. Therefore, when a water-in-oil droplet passes through the microelectrodes, the permittivity between the electrodes increases, thus increasing the capacitance value. In the experiment, droplets of lengths $68 \mu \mathrm{m}, 133 \mu \mathrm{m}$, and $248 \mu \mathrm{m}$ were generated by adjusting the pressure of oil and water phases. The LCR meter detected the capacitance values when they passed through the electrodes (electrode spacing: $40 \mu \mathrm{m}$ ). Figure $8 \mathrm{a}$ shows the detection results of $68 \mu \mathrm{m}$ droplets over $30 \mathrm{~s}$ at $0.1 \mathrm{MHz}$. Each droplet could generate a capacitive signal, and the average capacitance change $(\Delta \mathrm{C})$ was $11 \mathrm{fF}$. 
However, the capacitive signals fluctuated significantly. This is because a tiny droplet passed through the electrodes. The low sampling frequency for the LCR meter resulted in a significant measurement error.

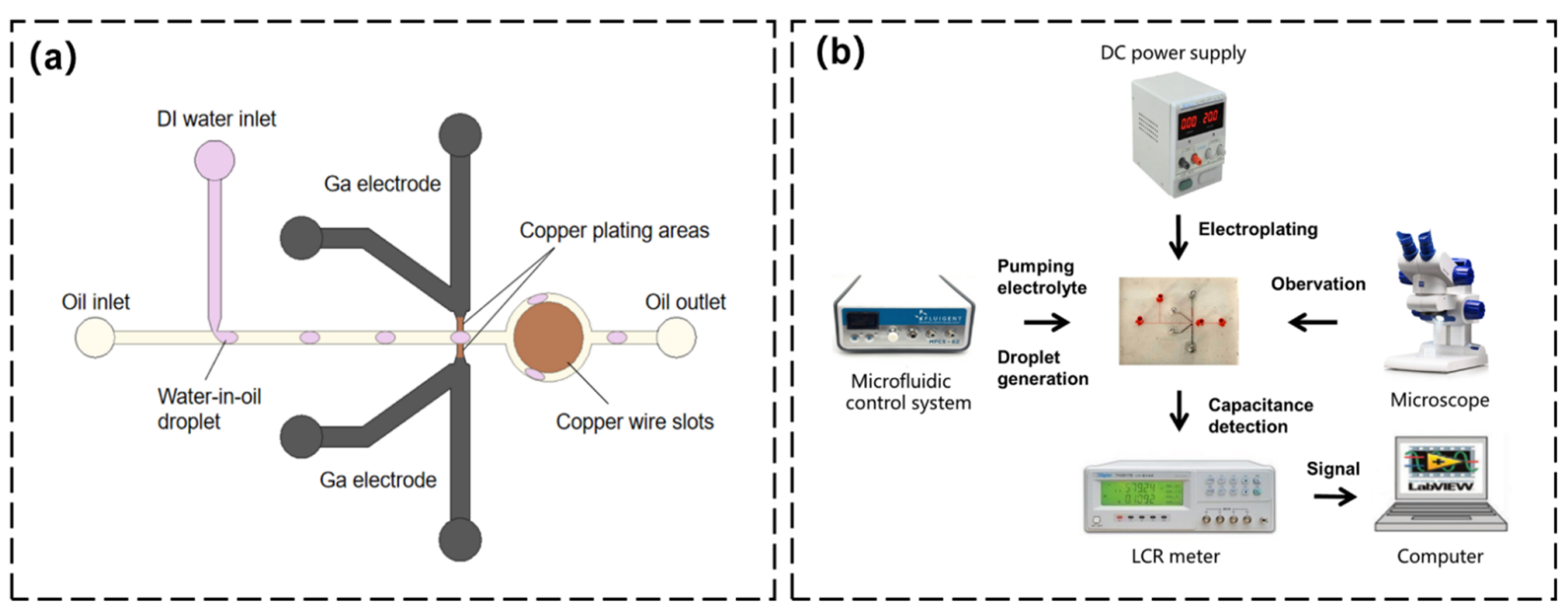

Figure 7. (a) The structure of a droplet detection sensor based on the microelectroplating electrode. (b) Diagram of the test setup.
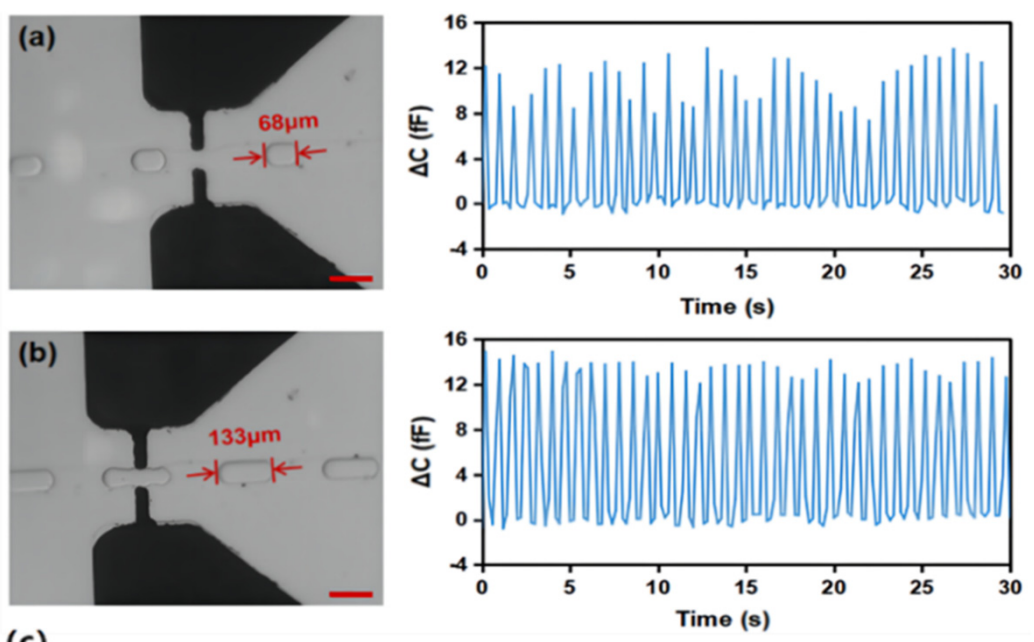

(c)
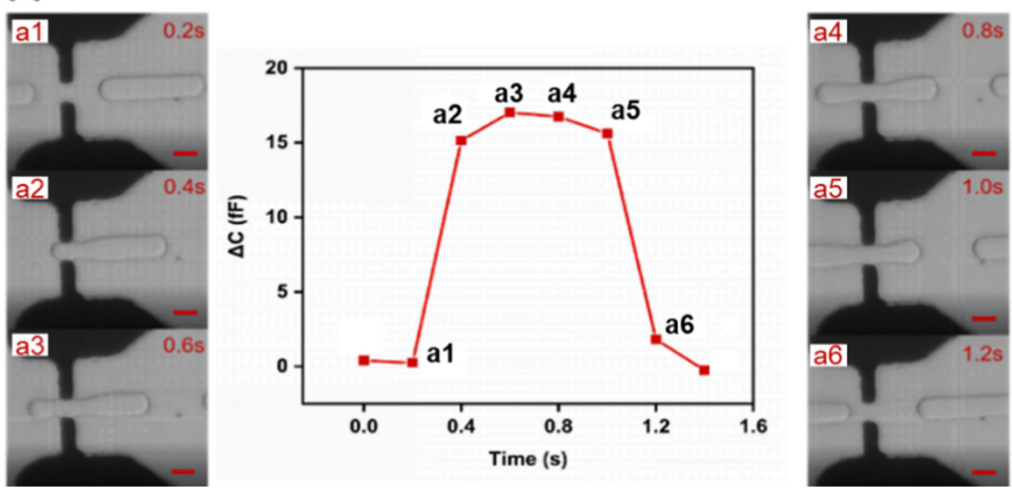

Figure 8. Droplet capacitance detection: (a) Capacitance signal caused by $68 \mu \mathrm{m}$ droplets over 30 s. Scale bar, $100 \mu \mathrm{m}$. (b) Capacitance caused by $133 \mu \mathrm{m}$ droplets over $30 \mathrm{~s}$. Scale bar, $100 \mu \mathrm{m}$. (c) Capacitance response process caused by a $248 \mu \mathrm{m}$ droplet. Subfigures a1-a6 show the position of the droplet at different times. Scale bar, $50 \mu \mathrm{m}$. 
Nevertheless, for $133 \mu \mathrm{m}$ droplets, the measurement results improved, as shown in Figure $8 \mathrm{~b}$. The average $\Delta \mathrm{C}$ caused by $133 \mu \mathrm{m}$ droplets over $30 \mathrm{~s}$ could reach $14 \mathrm{fF}$ at $0.1 \mathrm{MHz}$, making the signals more stable. Figure $8 \mathrm{c}$ recorded the real-time capacitance changes of the whole process of a $248 \mu \mathrm{m}$ droplet passing through the electrode. In the figure, a1 $(t=0.2 \mathrm{~s})$ is the location before the droplet entered the electrode region, and a2, $\mathrm{a} 3, \mathrm{a} 4$, and $\mathrm{a} 5$ are the locations of the microelectrode region at $\mathrm{t}=0.4 \mathrm{~s}, 0.6 \mathrm{~s}, 0.8 \mathrm{~s}$, and $1.0 \mathrm{~s}$, respectively. The capacitance reached the maximum at a3, where the $\Delta \mathrm{C}$ was $17 \mathrm{fF}$. The droplet left the microelectrode region completely at a6. Thus, the capacitance returned to the initial value. The above results suggest that this microdistance microelectrode based on microelectroplating can count droplets with different lengths and record the capacitance response process of a long droplet.

\subsection{Metal Particle Counting in Oil}

Metal particle pollution in oil [38-41] is one of the major causes of mechanical failure. The material, size, and concentration of pollutants can reflect the working state of mechanical equipment. Therefore, metal particle counting in oil is significant to mechanical systems' safety and fault diagnosis. Common metal contamination particles include aluminum, iron, and copper. Shi et al. [42] fabricated a microsensor to count Fe and $\mathrm{Cu}$ particles in oil by the inductance principle. However, their device was mainly used for detecting large metal particles $(>30 \mu \mathrm{m})$. Murali et al. [43] fabricated a microfluidic counter for 10-25 $\mu \mathrm{m}$ aluminum capacitance detection in lubricating oil. However, the metal film electrodes were made by evaporation, which increased the chip fabrication cost and effort.

The microdistance microelectrodes based on liquid metal microelectroplating introduced in this paper are a better tool to detect smaller oil particles because the microdistance can improve the sensitivity of capacitance detection. The chip is also simple to fabricate. Consequently, we utilized this microelectrode to detect the capacitance of copper particles in the oil. First, a small number of copper particles (size: 5-20 $\mu \mathrm{m}$ ) was mixed and dispersed in silicone oil. Then, the oil was pumped into the DC channel of the microchip after the electroplating process. The LCR meter was used to detect the capacitance signal at the passing of oil particles. Since metal particles' permittivity approaches positive infinity at high frequency, the relative permittivity between the microelectrodes increases when a copper particle passes through the microelectrodes, increasing capacitance.

Optical and capacitance counting results of copper particles are shown in Figure 9a,b, respectively (real-time recording is shown in Movie S1). Eight copper particles (a-h) were recorded over $200 \mathrm{~s}$ through the electroplated microelectrodes. The distance between the microelectrodes was about $35 \mu \mathrm{m}$, and the particle size was approximately $8-15 \mu \mathrm{m}$ with irregular particle shapes. We selected the peak values that were far higher than the noise values of the LCR meter as the basis for particle counting. The average noise value was calculated as $0.2 \pm 0.1 \mathrm{fF}$. The $\Delta \mathrm{C}$ caused by different particles $(\mathrm{a}-\mathrm{h})$ was within 0.9-1.5 $\mathrm{fF}$ at $0.1 \mathrm{MHz}$. However, for smaller copper particles $(<8 \mu \mathrm{m})$, the resulting capacitive signals were covered by noise, making them unrecognizable. For comparison, we also utilized nonelectroplated liquid metal microelectrodes to detect copper particles in oil (Figure S4). However, due to excessive electrode spacing, no capacitance signal caused by copper particles could be detected by the LCR meter. It proved that this novel microdistance microelectrode based on microelectroplating has higher sensitivity to detect small oil particles.

For practical applications, we also believe that this highly sensitive capacitive sensing technology based on the microelectroplating process can monitor and evaluate biological or environmental samples of different components, sizes, and concentrations in real time. In biological applications, the biochip integrated with this capacitive sensor can achieve the collection, detection, and screening of biological droplets, such as sweat and urine, for health monitoring. For environmental applications, the sensor can monitor microparticle size and concentration of water or oil pollution in industries to evaluate the environmental indicators. 
(a)
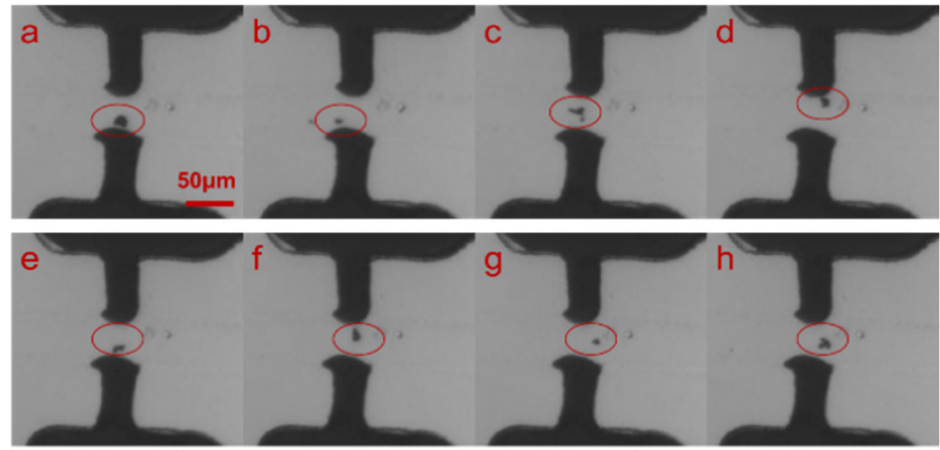

(b)

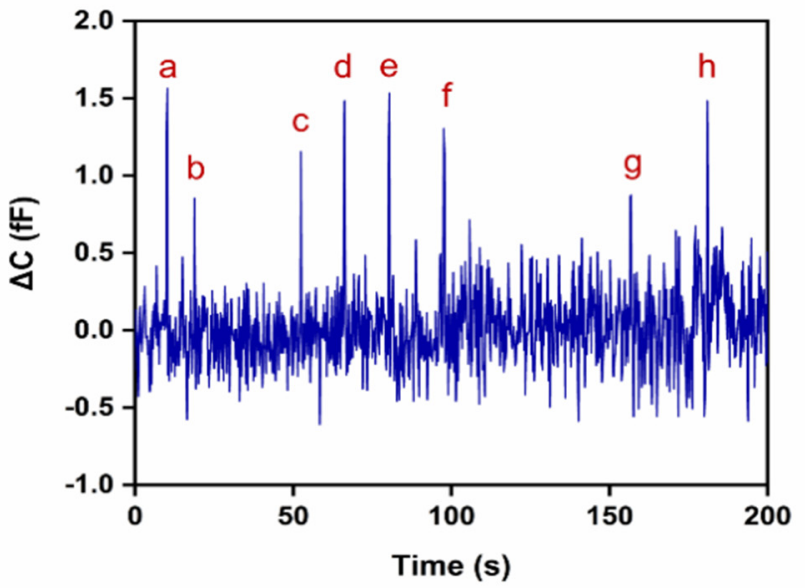

Figure 9. Metal particle counting in oil: (a) optical counting result of copper particles in oil over $200 \mathrm{~s}$. Subfigures $\mathbf{a}-\mathbf{h}$ indicate different copper particles passing through the electrodes, respectively; (b) the capacitance detection result of copper particles in oil over $200 \mathrm{~s}$ at $0.1 \mathrm{MHz}$.

\section{Conclusions}

This paper proposes a novel technology for the fabrication of microdistance sidewall microelectrodes based on liquid metal microelectroplating. This technology overcomes the complicated fabrication of traditional sidewall solid electrodes in microfluidics. The liquid metal electrode modified by electroplating has better stability than ordinary liquid electrodes as a contact-type electrode. In addition, sidewall microelectrodes with different microdistances can be more easily fabricated by this microelectroplating method, which significantly increases the detection sensitivity of microelectrodes. In applications, the sidewall microelectrodes fabricated by this technology also proved excellent capacitance detection performance, detecting $68-248 \mu \mathrm{m}$ microdroplets and 8-15 $\mu \mathrm{m}$ metal particles in the oil. Therefore, this novel method for microelectrode fabrication has definite value in manufacturing high-sensitivity microsensors in the future.

Supplementary Materials: The following supporting information can be downloaded at https:// www.mdpi.com/article/10.3390/s22051820/s1, Figure S1: The process of chip fabrication; Figure S2: Physical map of side-wall microelectroplated chip; Figure S3: Copper layer growth records every $30 \mathrm{~s}$ at different voltages; Figure S4: The optical and capacitance counting results of the nonelectroplated microelectrodes; Movie S1: Metal particle counting in oil.

Author Contributions: Conceptualization: J.G. and L.G.; data curation: J.G. and B.L.; methodology: J.G., L.G., B.L., P.Z., H.Z., L.G.; software: J.G.; validation: J.G. and L.G.; formal analysis: J.G., B.L. and P.Z.; investigation: J.G. and H.Z.; writing—original draft preparation: J.G.; writing-review and editing: L.G.; supervision: L.G.; funding acquisition: L.G. All authors have read and agreed to the published version of the manuscript. 
Funding: This work was funded by the National Key Research and Development Program of China (2019YFB2204903) and the Science and Technology Program from the State Grid Corporation of China (SGTYHT/21-JS-223).

Conflicts of Interest: The authors declare no conflict of interest.

\section{References}

1. Meagher, R.J.; Hatch, A.V.; Renzi, R.F.; Singh, A.K. An integrated microfluidic platform for sensitive and rapid detection of biological toxins. Lab Chip 2008, 8, 2046-2053. [CrossRef]

2. Sun, Y.; Quyen, T.L.; Hung, T.Q.; Chin, W.H.; Wolff, A.; Bang, D.D. A lab-on-a-chip system with integrated sample preparation and loop-mediated isothermal amplification for rapid and quantitative detection of Salmonella spp. in food samples. Lab Chip 2015, 15, 1898-1904. [CrossRef] [PubMed]

3. Nielsen, L.H.; Keller, S.S.; Boisen, A. Microfabricated devices for oral drug delivery. Lab Chip 2018, 18, 2348-2358. [CrossRef]

4. Abid, Z.; Strindberg, S.; Javed, M.M.; Mazzoni, C.; Vaut, L.; Nielsen, L.H.; Gundlach, C.; Petersen, R.S.; Mullertz, A.; Boisen, A.; et al. Biodegradable microcontainers-Towards real life applications of microfabricated systems for oral drug delivery. Lab Chip 2019, 19, 2905-2914. [CrossRef] [PubMed]

5. Wang, M.; Hu, L.; Xu, C. Recent advances in the design of polymeric microneedles for transdermal drug delivery and biosensing. Lab Chip 2017, 17, 1373-1387. [CrossRef] [PubMed]

6. Ueda, E.; Geyer, F.L.; Nedashkivska, V.; Levkin, P.A. Droplet Microarray: Facile formation of arrays of microdroplets and hydrogel micropads for cell screening applications. Lab Chip 2012, 12, 5218-5224. [CrossRef]

7. Segaliny, A.I.; Li, G.; Kong, L.; Ren, C.; Chen, X.; Wang, J.K.; Baltimore, D.; Wu, G.; Zhao, W. Functional TCR T cell screening using single-cell droplet microfluidics. Lab Chip 2018, 18, 3733-3749. [CrossRef]

8. Ye, N.; Qin, J.; Shi, W.; Liu, X.; Lin, B. Cell-based high content screening using an integrated microfluidic device. Lab Chip 2007, 7, 1696-1704. [CrossRef]

9. Zhou, H.; Yao, S. Electrostatic charging and control of droplets in microfluidic devices. Lab Chip 2013, 13, 962-969. [CrossRef]

10. Park, S.-Y.; Kalim, S.; Callahan, C.; Teitell, M.A.; Chiou, E.P.Y. A light-induced dielectrophoretic droplet manipulation platform. Lab Chip 2009, 9, 3228-3235. [CrossRef]

11. Esquivel, J.P.; Del Campo, F.J.; Gómez de la Fuente, J.L.; Rojas, S.; Sabaté, N. Microfluidic fuel cells on paper: Meeting the power needs of next generation lateral flow devices. Energy Environ. Sci. 2014, 7, 1744-1749. [CrossRef]

12. Zhang, Y.; Wang, H.; Meng, F.; Luo, Y.; Ling, F. Development status of microfluidic fuel cell. Chem. Ind. Eng. Prog. 2016, 35, 65-73

13. Ji, X.; Pan, J.; Zhou, J. Dielectrophoretic microfluidic chip with 3D vertical side-wall electrodes. In Proceedings of the 13th IEEE International Conference on Solid-State and Integrated-Circuit Technology (ICSICT), Hangzhou, China, 25-28 October 2016; pp. 269-271.

14. Kadilak, A.L.; Liu, Y.; Shrestha, S.; Bernard, J.R.; Mustain, W.E.; Shor, L.M. Selective deposition of chemically-bonded gold electrodes onto PDMS microchannel side walls. J. Electroanal. Chem. 2014, 727, 141-147. [CrossRef]

15. Kang, G.H.; No, K.Y.; Kim, G.M. Fabrication of microchannel with electrodes on side wall. Int. J. Mod. Phys. B 2006, 20, 4493-4498. [CrossRef]

16. Fava, E.L.; Silva, T.A.; Prado, T.M.D.; Moraes, F.C.; Faria, R.C.; Fatibello-Filho, O. Electrochemical paper-based microfluidic device for high throughput multiplexed analysis. Talanta 2019, 203, 280-286. [CrossRef]

17. Cao, J.T.; Zhu, Y.D.; Rana, R.K.; Zhu, J.J. Microfluidic chip integrated with flexible PDMS-based electrochemical cytosensor for dynamic analysis of drug-induced apoptosis on HeLa cells. Biosens. Bioelectron. 2014, 51, 97-102. [CrossRef]

18. Chen, Y.; Lu, S.; Zhang, S.; Li, Y.; Qu, Z.; Chen, Y.; Lu, B.; Wang, X.; Feng, X. Skin-like biosensor system via electrochemical channels for noninvasive blood glucose monitoring. Sci. Adv. 2017, 3, e1701629. [CrossRef] [PubMed]

19. Susloparova, A.; Koppenhoefer, D.; Law, J.K.Y.; Vu, X.T.; Ingebrandt, S. Electrical cell-substrate impedance sensing with fieldeffect transistors is able to unravel cellular adhesion and detachment processes on a single cell level. Lab Chip 2015, 15, 668-679. [CrossRef]

20. Scherer, B.; Surrette, C.; Li, H.; Torab, P.; Kvam, E.; Galligan, C.; Go, S.; Grossmann, G.; Hammond, T.; Johnson, T.; et al. Digital electrical impedance analysis for single bacterium sensing and antimicrobial susceptibility testing. Lab Chip 2021, 21, 1073-1083 [CrossRef]

21. Zhang, R.; Ye, Z.; Gao, M.; Gao, C.; Zhang, X.; Li, L.; Gui, L. Liquid metal electrode-enabled flexible microdroplet sensor. Lab Chip 2020, 20, 496-504. [CrossRef]

22. Zuo, Z.; Wang, K.; Gao, L.; Ho, V.; Mao, H.; Qian, D. A Novel Mass-Producible Capacitive Sensor with Fully Symmetric 3D Structure and Microfluidics for Cells Detection. Sensors 2019, 19, 325. [CrossRef] [PubMed]

23. Ali, M.M.; Narakathu, B.B.; Emamian, S.; Chlaihawi, A.A.; Aljanabi, F.; Maddipatla, D.; Bazuin, B.J.; Atashbar, M.Z. Eutectic Ga-In Liquid Metal Based Flexible Capacitive Pressure Sensor. In Proceedings of the 15th IEEE Sensors Conference, Orlando, FL, USA, 30 October-3 November 2016.

24. Shi, H.; Zhang, H.; Ma, L.; Rogers, F.; Zhao, X.; Zeng, L. An Impedance Debris Sensor Based on a High-Gradient Magnetic Field for High Sensitivity and High Throughput. IEEE Trans. Ind. Electron. 2021, 68, 5376-5384. [CrossRef] 
25. Choi, J.-W.; Rosset, S.; Niklaus, M.; Adleman, J.R.; Shea, H.; Psaltis, D. 3-dimensional electrode patterning within a microfluidic channel using metal ion implantation. Lab Chip 2010, 10, 783-788. [CrossRef] [PubMed]

26. Wang, L.; Flanagan, L.; Lee, A.P. Side-Wall Vertical Electrodes for Lateral Field Microfluidic Applications. J. Microelectromech. Syst. 2007, 16, 454-461. [CrossRef]

27. Harnett, C.K.; Templeton, J.; Dunphy-Guzman, K.A.; Senousy, Y.M.; Kanouff, M.P. Model based design of a microfluidic mixer driven by induced charge electroosmosis. Lab Chip 2008, 8, 565-572. [CrossRef]

28. Richards, A.L.; Dickey, M.D.; Kennedy, A.S.; Buckner, G.D. Design and demonstration of a novel micro-Coulter counter utilizing liquid metal electrodes. J. Micromech. Microeng. 2012, 22, 115012. [CrossRef]

29. Gao, M.; Gui, L. Development of a Multi-Stage Electroosmotic Flow Pump Using Liquid Metal Electrodes. Micromachines 2016, 7, 165. [CrossRef]

30. So, J.H.; Dickey, M.D. Inherently aligned microfluidic electrodes composed of liquid metal. Lab Chip 2011, 11, 905-911. [CrossRef]

31. Li, S.; Li, M.; Hui, Y.S.; Cao, W.; Li, W.; Wen, W. A novel method to construct 3D electrodes at the sidewall of microfluidic channel. Microfluid. Nanofluid. 2013, 14, 499-508. [CrossRef]

32. Wang, Q.; Gao, M.; Zhang, L.; Deng, Z.; Gui, L. A Handy Flexible Micro-Thermocouple Using Low-Melting-Point Metal Alloys. Sensors 2019, 19, 314. [CrossRef]

33. Luo, J.; Simon, M.G.; Jiang, A.Y.L.; Nelson, E.L.; Lee, A.P.; Li, G.-P.; Bachman, M. 3-D In-Bi-Sn Electrodes for Lab-on-PCB Cell Sorting. IEEE Trans. Compon. Packag. Manuf. Technol. 2016, 6, 1295-1300. [CrossRef]

34. Akita, T.; Tomie, M.; Ikuta, R.; Egoshi, H.; Hayase, M. Observation of the Behavior of Additives in Copper Electroplating Using a Microfluidic Device. J. Electrochem. Soc. 2018, 166, D3058-D3065. [CrossRef]

35. Bao, B.; Ji, B.; Wang, M.; Gao, K.; Yang, B.; Chen, X.; Wang, X.; Liu, J. Development and characterisation of electroplating silver/silver chloride modified microelectrode arrays. Micro Nano Lett. 2019, 14, 299-303. [CrossRef]

36. Polk, B.J.; Bernard, M.; Kasianowicz, J.J.; Misakian, M.; Gaitan, M. Microelectroplating Silver on Sharp Edges toward the Fabrication of Solid-State Nanopores. J. Electrochem. Soc. 2004, 151, C559. [CrossRef]

37. Zheng, W.; Guo, Z.; Luo, H.; Jiang, S.; Mo, Y. Comparison Between Micro-chemical Etching and Microelectroplating Processes for Preparing Metal Mold of Microfluidic Chip. Corros. Sci. Prot. Technol. 2015, 27, 264-268.

38. He, Q.; Chen, G.; Chen, X.; Yao, C. Application of Oil Analysis to the Condition Monitoring of Large Engineering Machinery. In Proceedings of the 8th International Conference on Reliability, Maintainability and Safety (ICRMS 2009), Chengdu, China, 20-24 July 2009.

39. Ma, S.; Yang, D.; Liang, B.; Jin, Y. Impact of metal particle size on partial discharge characteristics of moving metal particles in transformer oil. Chem. Phys. Lett. 2019, 731, 136577. [CrossRef]

40. Wang, Y.; Zhang, M.; Liu, D. A Compact On-line Particle Counter Sensor for Hydraulic Oil Contamination Detection. In Proceedings of the 3rd International Conference on Mechanical and Electronics Engineering (ICMEE 2011), Hefei, China, 23-25 September 2012.

41. Zhang, R.-c.; Yu, X.; Hu, Y.-1.; Zang, H.-j.; Shu, W. Active control of hydraulic oil contamination to extend the service life of aviation hydraulic system. Int. J. Adv. Manuf. Technol. 2018, 96, 1693-1704. [CrossRef]

42. Shi, H.; Zhang, H.; Ma, L.; Sun, Y.; Chen, H.; Zhao, X.; Bai, C.; Zhang, Y. Inductive-Capacitive Coulter Counting: Detection and Differentiation of Multi-Contaminants in Hydraulic Oil Using a Microfluidic Sensor. IEEE Sens. J. 2021, 21, 2067-2076. [CrossRef]

43. Murali, S.; Jagtiani, A.V.; Xia, X.; Carletta, J.; Zhe, J. A microfluidic Coulter counting device for metal wear detection in lubrication oil. Rev. Sci. Instrum. 2009, 80, 016105. [CrossRef] 